\title{
Human Breast Adipose-Derived Stem Cells Transfected with the Stromal Cell-Derived Factor-1 Receptor CXCR4 Exhibit Enhanced Viability in Human Autologous Free Fat Grafts
}

\author{
Fang-tian Xua Hong-mian Lib Qing-Shui Yinc Da-lie Liud Hua Nan ${ }^{d}$ Pei-ran Zhao \\ Shuang-wu Liange \\ aDepartment of Orthopedics, the First Affiliated Hospital of Gannan Medical University, Ganzhou, \\ ${ }^{b}$ Department of Plastic and Aesthetic Surgery, the Affiliated Nanning First People's Hospital of Guangxi \\ Medical University, Nanning, 'Department of Orthopedic Surgery, Guangzhou General Hospital of \\ PLA, Guangzhou, 'Department of Plastic and Reconstructive Surgery, Zhujiang Hospital of Southern \\ Medical University, Guangzhou, e'Research Center for Tissue Engineering, Southern Medical University, \\ Guangzhou, China
}

\section{Key Words}

Fat graft - Human breast adipose-derived stem cells - Angiogenesis - Revascularization CXCR4

\footnotetext{
Abstract

Background: The main complication of autologous free fat tissue transplantation is fat resorption and calcification due to the ischemic necrosis of fat. The promotion of transplant neovascularization soon after autologous free fat grafts may reduce these outcomes. In adulthood, stromal cell-derived factor- 1 (SDF-1) and its membrane receptor C-X-C chemokine receptor type 4 (CXCR4) are involved in the homing and migration of multiple stem cell types, neovascularization, and cell proliferation. We hypothesized that CXCR4 may improve the long-term survival of free fat tissue transplants by recruiting endothelial progenitor cells (EPCs) and may therefore improve graft revascularization. In this study, we aimed to determine the effect of human breast adipose-derived stem cells (HBASCs) transfected with the CXCR4 gene on the survival rate of human autologous free fat transplants in nude mice. Methods: Human breast adipose-derived stem cells (HBASCs) were expanded ex vivo for 3 passages, labeled with green fluorescent protein (GFP) and transfected with CXCR4 or left untransfected. Autologous fat tissues were mixed with the GFP-labeled, CXCR4-transfected HBASCs (group A), GFP-labeled HBASCs (group B), the known vascularization-promoting agent VEGF (group C), or medium (group D) and then injected subcutaneously into 32 nude mice at 4 spots in a random fashion. Six months later, the transplanted tissue volume and histology were H.-m. Li, F.-t. Xu and Q.-S.Yin contributed equally to this work as co-first authors 
evaluated, and neo-vascularization was quantified by counting the capillaries. CXCR4 and SDF-1 $\alpha$ mRNA expression in the transplants was determined using real-time quantitative PCR analysis (qPCR). Results: The data revealed that the control (group $D$ ) transplant volume survival was $28.3 \pm 4.5 \%$. Mixing CXCR4-transfected (group A) and untransfected (group B) HBASCs significantly increased transplant volume survival $(79.5 \pm 8.3 \%$ and $67.2 \pm 5.9 \%$, respectively), whereas VEGF-transfected HBASCs (group C) were less effective (41.2 $\pm 5.1 \%$ ). Histological analysis revealed that both types of HBASCs-treated transplants consisted predominantly of adipose tissue, unlike the control transplants, and also presented significantly less fat necrosis and fibrosis. The CXCR4-transfected HBASCs-treated transplants had a significantly higher capillary density than did the other transplants and showed GFP and CD31 double-positive cells (i.e., ASCs-derived endothelial cells). The mRNA expression of CXCR4 and SDF-1 $\alpha$ was much higher in the CXCR4-transfected HBASCs transplants than in the other three transplants. Conclusions: Our data demonstrated that HBASCs can enhance the survival and quality of transplanted free fat tissues. Moreover, CXCR4 transfection of these HBASCs could augment this effect. Stimulation of angiogenesis and decreased fat cell apoptosis due to the recruitment of endothelial progenitor cells (EPCs) and an increase in graft revascularization are potential mechanisms underlying the improved long-term survival of free fat transplants following CXCR4-transfected HBASCs treatment.

Copyright $\odot 2014$ S. Karger AG, Basel

\section{Introduction}

Adipose tissue has been used as an autologous, natural filler for soft tissue defects because antigenic and allergic reactions are minimized. Given these advantages, autologous fat transplantation is a useful technique during plastic and reconstructive surgery. Clinically, adipose tissues are removed from the belly or thigh by liposuction, as this simple procedure reduces stress on the patient. However, compared with non-suctioned adipose tissues, suctioned fat tissues contain fewer multipotent adipose-derived stem cells (ASCs) and mostly damaged adipocytes because of the centrifugation step used to concentrate and separate adipocytes from the debris, which includes blood cells, lipids, proteases, and other components [1-5]. The relative deficiency of multipotent ASCs contributes to the unpredictable partial absorption, low survival rate, and long-term atrophy of transplanted lipoaspirates, and repeated lipotransplantation is often necessary [5-8]. To address these issues, many clinical methods have been utilized in attempts to enhance the viability and survival rate of transplanted fat tissues [6, 7, 9-11]. Several reports have demonstrated that grafted fat has an increased survival rate when transplanted with the stromal vascular fraction (i.e., ASCs) obtained from alternative liposuction aspirates enriched in ASCs [5-8]. This strategy, termed cell-assisted lipotransfer (CAL), has proven to be effective, safe, and superior to conventional lipoinjection used in common procedures, such as breast reconstruction, cosmetic breast augmentation, and facial lipoatrophy [6-7]. However, the efficiency of CAL in terms of the survival duration of engrafted fat still varies depending on the individual.

Many previous studies have shown that the fate of transplanted fat tissue depends on the adequacy of blood perfusion during the early stages after transplantation [12]. Thus, measures that enhance vascularization of the transplanted fat tissue early after transplantation are likely to increase the viability of the transplant. Recent advances in vascular biology have suggested possible targets that can be manipulated to increase ischemic tissue survival [13]. One of these targets is vascular endothelial growth factor (VEGF). The ability of exogenous VEGF (and other agents) to stimulate the development of new blood vessels has been investigated. It has been shown that when VEGF is applied topically or injected intravenously, it enhances the revascularization of ischemic tissues, such as skin flaps [14]. However, the effect of this exogenous cytokine administration is limited by the number of endothelial cells in the transplant. Thus, an alternative, or adjunct, strategy is to increase the number of endothelial cells in the transplant [15]. 
Chemokines are potent chemoattractant cytokines that regulate leukocyte trafficking in homeostatic and inflammatory processes. More than 50 distinct chemokines and 20 chemokine receptors have been cloned [16]. Chemokines usually bind to multiple receptors, and the same receptor may bind to more than one chemokine. However, stromal cell derived factor-1 (SDF-1), which binds exclusively to CXCR4, is an exception to this rule [17]. Recently, a new putative receptor for SDF-1, termed CXCR7 and also known as RDC1 and GPR159, has been described [18]; however, its potential role in the regulation of cell trafficking awaits confirmation by other laboratories. The CXCR4/SDF-1 signaling axis plays an important role in normal physiology and is also known to promote angiogenesis, local and distal metastasis, and cell survival [19]. Because CXCR4 is an important player in angiogenesis, we hypothesized that CXCR4 may improve the long-term survival of free fat tissue transplants by recruiting endothelial progenitor cells (EPCs) from the bone marrow through a CXCR4dependent mechanism. In this study, we investigated the effect of HBASCs transfected with the CXCR4 gene on the survival rate of human autologous free fat transplants in nude mice. HBASCs transfected with the CXCR4 gene were mixed with fat tissue and injected into nude mice. The retained fat volume and the graft histology were evaluated.

\section{Materials and Methods}

\section{Sources and preparation of human fat tissue}

Fat tissue was harvested from the abdomen of a 30-year-old healthy woman undergoing suctionassisted liposuction under extradural anesthesia. Prior to the start of the operation, the areas for liposuction were injected with a local anesthetic solution containing lidocaine $(0.5 \%)$ and adrenaline $(1: 100,000)$ to decrease bleeding during liposuction and to relieve pain after the procedure. The fat tissue was aspirated using a 16-gauge three-hole blunt cannula and processed under sterile conditions for subsequent grafting into nude mice within two hours. The participant gave her written informed consent, and the study was reviewed and approved by the institutional review board.

\section{Isolation and expansion of human breast adipose-derived stem cells (HBASCs)}

The HBASCs were isolated from spare fat tissue from the same patient who underwent reduction mammoplasty. The fat tissue was cut into small sections and then washed with phosphate-buffered saline (PBS) to eliminate red blood cells. Then, the adipose tissue was finely minced and digested with $0.1 \%$ collagenase for $60 \mathrm{~min}$ at $37^{\circ} \mathrm{C}$ with vigorous agitation. Following centrifugation at $260 \times \mathrm{g}$ for $5 \mathrm{~min}$, the cell pellet, which mainly included HBASCs, was resuspended with Dulbecco's modified Eagle's medium (DMEM) plus $10 \%$ fetal bovine serum (FBS). The suspended cells were seeded onto dishes to expand the HBASCs. The cultures were incubated at $37^{\circ} \mathrm{C}$ with $5 \%$ carbon dioxide. The medium was first changed $24 \mathrm{~h}$ after seeding, and nonadherent cells were discarded. Thereafter, the medium was replaced every 3 days. The specific differentiation medium and culture conditions are described in the subsequent results sections. Cultured cells were observed under a microscope to assess expansion and cell morphology. Cells were harvested at $80-90 \%$ confluence and passaged at a ratio of $1: 3$. To confirm the multilineage differentiation capacity of the isolated HBASCs, sub-confluent HBASCs from the third passage were cultured using adipogenic, osteogenic and chondrogenic inductive media (Table 1). After two or three weeks of induction, HBASCs differentiation was detected using the relevant histological assays.

\section{Immunofluorescence and immunohistochemistry}

To identify the specific cellular surface markers CD29, CD31, CD34, CD44, CD49d, CD90 and CD105, immunofluorescence staining was performed on HBASCs at the third passage. The primary antibodies used were monoclonal mouse anti-human (1:200, Sigma, Santa Clara, CA, USA), and the secondary antibodies were goat anti-mouse IgG-Cy3 (CD29, CD31, CD34 and CD90) or IgG-FITC (CD44, CD49d and CD105) (all 1:100, Sigma). The nuclei of CD29-, CD31-, CD34-, CD49d-, CD90- and CD105-stained HBASCs were counterstained with 4',6-diamidino-2-phenylindole dihydrochloride (DAPI), whereas the nuclei of CD44stained HBASCs were counterstained with propidium iodide (PI). 
Table 1. Multilineage induction of HBASCs.

\begin{tabular}{|c|c|c|}
\hline & Induction & Characterization \\
\hline Adipogenic & $\begin{array}{l}\text { DMEM (high glucose), 10\% FBS, } 1 \% \text { antibiotic/antimycotic, } 200 \mu \mathrm{M} \text { indomethacin, } \\
0.5 \mathrm{mM} \text { isobutyl-methylxanthine (IBMX), } 1 \mu \mathrm{M} \text { dexamethasone, } 10 \mu \mathrm{M} \text { insulin }\end{array}$ & Oil red O staining \\
\hline Osteogenic & $\begin{array}{l}\text { DMEM (high glucose), } 10 \% \text { FBS, } 1 \% \text { antibiotic/antimycotic, } 0.1 \mu \mathrm{M} \\
\text { dexamethasone, } 50 \mu \mathrm{g} / \mathrm{ml} \text { ascorbate-2-phosphate, } 10 \mathrm{mM} \beta \text {-glycerophosphate }\end{array}$ & $\begin{array}{l}\text { Alizarin red } \\
\text { staining }\end{array}$ \\
\hline Chondrogenic & $\begin{array}{l}\text { DMEM (high glucose), } 1 \% \text { FBS, } 10 \mathrm{ng} / \mathrm{ml} \text { TGF- } \beta 1,1 \% \text { antibiotic/antimycotic, } 6.25 \\
\mu \mathrm{g} / \mathrm{ml} \text { insulin, } 50 \mathrm{nM} \text { ascorbate-2-phosphate }\end{array}$ & $\begin{array}{l}\text { Alcian blue } \\
\text { staining }\end{array}$ \\
\hline
\end{tabular}

Adenoviral infection of HBASCs

We generated the adenovirus used to express CXCR4 using the AdEasy system labeled with GFP. HBASCs at the third passage were transfected with the CXCR4-encoding adenovirus when upon reaching approximately $90 \%$ confluence based on examination under fluorescence microscopy. Prior to infection, the cells were washed with infection buffer three times and incubated at room temperature (RT) for 10 min. Infection was carried out with a multiplicity of infection (MOI) of $50 \mathrm{pfu} / \mathrm{cell}$ in $1 \mathrm{ml}$ of infection buffer at RT for $60 \mathrm{~min}$. After infection, the HBASCs were incubated for the indicated time periods at $37^{\circ} \mathrm{C}$ with $5 \%$ carbon dioxide in a humidified atmosphere. Three days later, HBASCs at the third passage were collected and used in this study.

\section{Expression of human CXCR4 protein and secretion of SDF-1 $\alpha$ in vitro}

After 3 days of culture, CXCR4-transfected HBASCs were washed once and fixed with 4\% (volume/ volume) paraformaldehyde in phosphate-buffered saline for immunofluorescence staining. The primary antibody was rabbit anti-human CXCR4 (Santa Cruz Biotechnology), and a FITC-conjugated goat anti-rabbit secondary antibody was used. The HBASCs were incubated with each antibody for 45 minutes at room temperature. Positive CXCR4 expression was determined by observing stained cells under a fluorescence microscope.

After 72 hours of culture, 10 samples from the control (untransfected) and test (transfected) groups were harvested for western blot analysis. Whole-cell extracts were obtained from two groups of differentiated HBASCs. Briefly, confluent cells were washed with ice-cold PBS and removed by scraping. Cell pellets were sonicated in the extraction buffer. Extracts were quantified using the BioRad DC protein assay kit (BioRad, Hercules, CA, USA). Equal amounts of protein were resolved on 4-12\% SDS-PAGE and transferred to PVDF membranes (Millipore, Bedford, MA, USA). The membranes were then blocked with blocking solution (Pierce, Rockford, IL, USA). The primary antibody used was anti-human CXCR4 (Abcam Co. Ltd., London, UK). A horseradish peroxidase-conjugated secondary antibody and an enhanced chemiluminescence substrate (Super-signal West Dura Detection System, Pierce) were used to detect the primary antibody.

The cell culture medium was collected $1,3,5,7,9,11$ and 13 days after gene transfection, and the SDF-1 $\alpha$ levels in the medium were quantified using a human SDF- $1 \alpha$ immunoassay kit (R\&D Systems, Inc., Minneapolis, Minn.). The absorbance was measured at $450 \mathrm{~nm}$ using a microplate reader.

\section{Establishment of the animal model and groups}

All animal procedures were performed in accordance with the guidelines of the Southern Medical University Animal Care and Use Committee. Thirty-two nude mice (average weight, $20.0 \mathrm{~g} \pm 4.0 \mathrm{~g}$ ) served as free fat transplantation models. Sharp 16-gauge needles were used to inject each mouse subcutaneously at 4 spots with fat tissue $(0.5 \mathrm{ml} / \mathrm{spot})$ that had been mixed with $0.1 \mathrm{ml}$ of $1 \times 10^{7} / \mathrm{ml}$ GFP-labeled CXCR4transfected HBASCs (group A), $0.1 \mathrm{ml}$ of $1 \times 10^{7} / \mathrm{ml} \mathrm{GFP-labeled} \mathrm{HBASCs} \mathrm{(group} \mathrm{B),} 0.1 \mathrm{ml}$ of $1 \mu \mathrm{g} / \mathrm{ml} \mathrm{VEGF}$ (group C), or $0.1 \mathrm{ml}$ of DMEM (group D). Each mouse was potentially injected with all four fat mixtures, as each of the four fat mixtures was injected in a random fashion. After 6 months, the transplants were excised and analyzed as described below.

\section{Histopathological examination of transplants}

Formalin-fixed transplants from the four groups were embedded in paraffin. Tissue sections from the center of the dissected fat biopsy were stained with hematoxylin-eosin using standard procedures and examined under a light microscope. Tissue sections from the center of the dissected fat biopsy were embedded in paraffin for conventional HE-based histological assessment, and neovascularization was assessed by counting the capillaries in 10 fields of each HE-stained slide (40× magnification; counting was performed by two blinded reviewers) and then calculating the capillary density. 
Table 2. Levels of SDF- $1 \alpha$ at each time point in the two groups (mean $\pm S D, n=10$ ). Transfected group vs. untransfected group, $* \mathrm{P}<0.01$, Student's t-test

\begin{tabular}{lll}
\hline $\begin{array}{l}\text { Culture time } \\
\text { (days) }\end{array}$ & $\begin{array}{c}\text { SDF-1 } \alpha(\mathrm{ng} / \mathrm{ml}) \\
\text { Transfected group }\end{array}$ & Untransfected group \\
\hline 1 & $95.66 \pm 10.32^{*}$ & $23.15 \pm 3.71$ \\
3 & $173.47 \pm 18.12^{*}$ & $26.33 \pm 3.94$ \\
5 & $281.85 \pm 29.27^{*}$ & $25.46 \pm 4.02$ \\
7 & $312.91 \pm 35.26^{*}$ & $27.08 \pm 4.29$ \\
9 & $261.83 \pm 28.75^{*}$ & $29.03 \pm 4.62$ \\
11 & $253.32 \pm 29.05^{*}$ & $25.95 \pm 5.07$ \\
13 & $238.59 \pm 25.73^{*}$ & $31.02 \pm 5.87$ \\
\hline
\end{tabular}

Table 3. Primer sequences

\begin{tabular}{lll}
\hline Gene name (human) & Forward primer sequence (5' to $\left.3^{\prime}\right)$ & Reverse primer sequence $\left(5^{\prime}\right.$ to $\left.3^{\prime}\right)$ \\
\hline CXCR4 & GGCCGTCTATGTGGGTGTCTGG & TGGCCCTTGGAGTGTGACAG \\
SDF-1 $\alpha$ & CCAAGGTCGTCGCCGTGCT & TGACGTTGGCTCTGGCGATGT \\
GAPDH & GAAGGTGAAGGTCGGAGTC & GAAGATGGTGATGGGATTTC \\
\hline
\end{tabular}

The origin of endothelial cells in neovascular capillaries

Transplant samples were embedded for frozen sectioning and cut into 5-mm-thick slices. CD31 staining was used to detect capillary endothelial cells. Briefly, after blocking, slides were stained overnight at $4^{\circ} \mathrm{C}$ with monoclonal mouse anti-human CD31 (1:200, Sigma, Santa Clara, CA, USA) and then incubated with goat anti-mouse IgG-Cy3 (1:100, Sigma) antibody for $45 \mathrm{~min}$. After washing with PBS twice, the slides were placed under a green fluorescent beam to detect the red fluorescence of Cy3. After images were obtained, the slides were placed under a blue fluorescent beam, allowing detection of the GFP-labeled exogenous HBASCs. The green and red fluorescent images were merged using imaging software (LuminaVison; V220 Olympus). Overlapping red and green fluorescence produced a yellow color, which indicated that the endothelial cells in the neovascular capillaries were derived from the transplanted GFP-positive HBASCs.

Real-time quantitative PCR analysis ( $($ PCR) of the transplants after 6 months

Total RNA was extracted from each group using the TRIzol method strictly following the manufacturer's protocol (Invitrogen, USA). First-strand cDNA was synthesized from $1 \mu \mathrm{g}$ of RNA using viral reverse transcriptase (TaKaRa, Japan) and used for quantitative real-time PCR. The expression levels of representative genes, including CXCR4 and SDF- $1 \alpha$, were quantified using an ABI 7300 real-time PCR system (Applied Biosystems, USA) and SYBR green PCR reaction mix (TaKaRa, Japan). The primers used to amplify each gene are listed in Table 3 . The program used included the following steps: $95^{\circ} \mathrm{C}$ for $5 \mathrm{~min}$, followed by 40 cycles of $95^{\circ} \mathrm{C}$ for $15 \mathrm{~s}$, annealing temperature for $1 \mathrm{~min}$, and $72^{\circ} \mathrm{C}$ for $30 \mathrm{~s}$. Melting curve analysis and agarose gel electrophoresis were performed to confirm the specificity of the PCR products. The relative expression levels of the genes were analyzed using the $2-\Delta \Delta \mathrm{Ct}$ method by normalization against the expression of the housekeeping gene GAPDH. The results are presented as fold increases relative to the control group.

\section{Statistical analysis}

Because each mouse was randomly injected with the four fat tissues at 4 spots, we performed analysis of variance to determine whether the means of all four groups were equal. This approach considers withinsubject variation and between-subject variation. Furthermore, if the analysis of variance of the four means revealed significant differences, multiple comparisons of the means of any two groups were made by using the paired $t$-test. Differences in means were regarded as statistically significant if the two-tailed $p$ value was less than 0.05. All data were analyzed using SPSS for Windows version 16.0 (Chicago, IL, USA) and presented as the means $\pm \mathrm{SD}$.

\section{Results}

Characterization and multipotency of HBASCs.

Following their initial isolation and expansion, homogeneous HBASCs that had grown in a monolayer and exhibited a spindle-shaped morphology were observed following culture for one to two weeks (Fig. 1A). These HBASCs presented a strong capacity for 

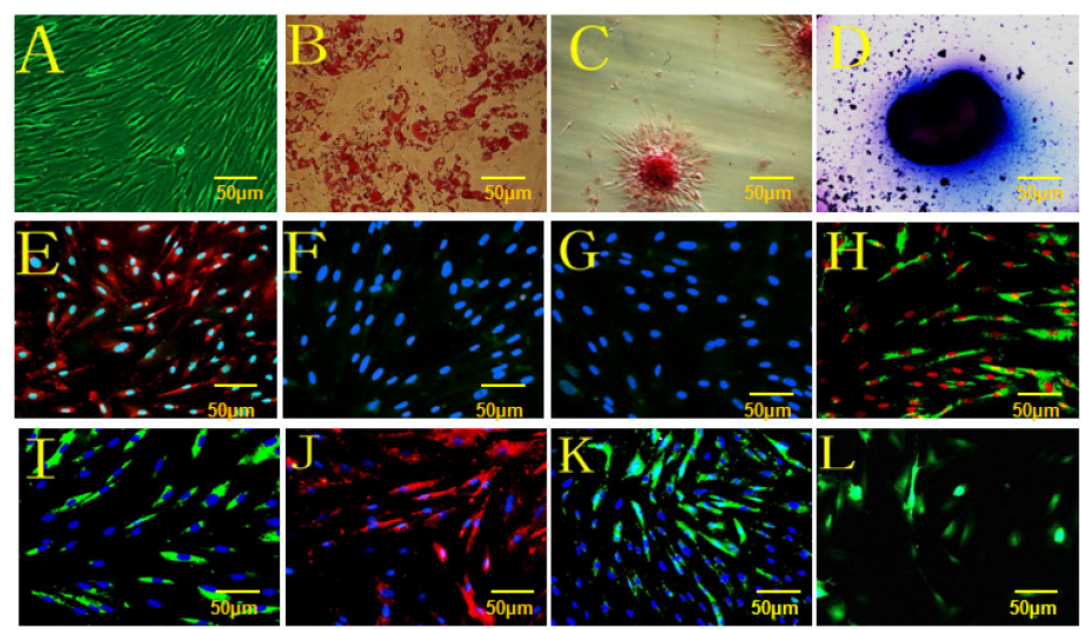

Fig. 1. Characterization of HBASCs prior to and following induction. (A) HBASCs at passage three were stained with the following agents: (B) oil red 0 following adipogenic induction for 2 weeks; (C) alizarin red following osteogenic induction for 3 weeks; and (D) alcian blue following chondrogenic induction for 2 weeks. (E-K) Immunofluorescence staining was performed for CD29, CD31, CD34, CD44, CD49d, CD90 and CD105. Scale bars: $50 \mu \mathrm{m}$. (L) HBASCs were labeled with GFP. Scale bars: $50 \mu \mathrm{m}$.

proliferation. The HBASCs reached $80-90 \%$ confluence 7 days after the initial seeding for the first passage. Confluence was achieved within 3-4 days with a 1:3 split ratio. These observations demonstrated that HBASCs resemble bone mesenchymal stem cells (BMSCs) in terms of their morphology and proliferation capacity. Subconfluent HBASCs at passage 3 were cultured for 1-2 weeks with adipogenic, osteogenic and chondrogenic induction media. Lineage-specific cell morphologies were observed following 2, 3 and 2 weeks of culture in adipogenic, osteogenic and chondrogenic media, respectively. Adipocytes, osteoblasts and chondrocytes can be identified by positive oil Red 0 , alcian blue and immunohistochemical staining, respectively. Thus, lineage-specific histological staining was performed using these dyes, and the results confirmed that the HBASCs differentiated into adipocytes, osteoblasts and chondrocytes following culture in the relevant induction medium (Fig. 1B, C, D). These results validated the multipotency of HBASCs.

It has been reported that MSCs derived from distinct tissue sources express similar but nonidentical patterns of cell surface markers, possibly due to differences in the tissue source and donor age. CD44, CD90 and CD105 are the main three positive markers for MSCs. Although CD31 and CD34 are the most frequently reported negative markers, CD49d has been reported as a positive marker and as a negative marker in certain studies. To define the cellular features of HBASCs, the abovementioned cell surface markers were all analyzed in the HBASCs isolated in the present study. HBASCs at the third passage were subjected to immunofluorescence staining with antibodies against these marker proteins. The immunofluorescence staining results revealed that these HBASCs expressed CD29, CD44, CD49d, CD90 and CD105 (>90\% of the cells exhibited positive staining, Fig. 1E, H, I, J and $\mathrm{K})$; however, expression of CD31 or CD34 were not observed $(<5 \%$ of the cells are exhibited positive staining; Fig. 1F and G). Green nuclei were observed in HBASCs when the cells were labeled with GFP (Fig. 1L).

CXCR4 protein expression and levels of SDF-1 $\alpha$ after transfection of HBASCs with CXCR4

The HBASCs were transfected with the human CXCR4 gene with a multiplicity of infection (MOI) of $50 \mathrm{pfu} /$ cell. When immunofluorescence staining for CXCR4 was performed 3 days later, over $90 \%$ of the HBASCs were positive for CXCR4 (Fig. 2A). In contrast, the untransfected HBASCs exhibited low levels of CXCR4 expression (Fig. 2B). 
Fig. 2. CXCR4 transgene expression in vitro $(100 \times$ magnification) A: Over $90 \%$ of the CXCR4-transfected HBASCs stained positively for CXCR4 three days after transduction. B: Minimal CXCR4 expression was observed in the untransfected HBASCs. C: CXCR4 protein expression was examined according to western blot in transfected or untransfected HBASCs. D: The level of SDF- $1 \alpha$ secretion by the CXCR4-transduced HBASCs increased significantly over time after transduction and peaked on day 7. Scale bars: $50 \mu \mathrm{m}$.
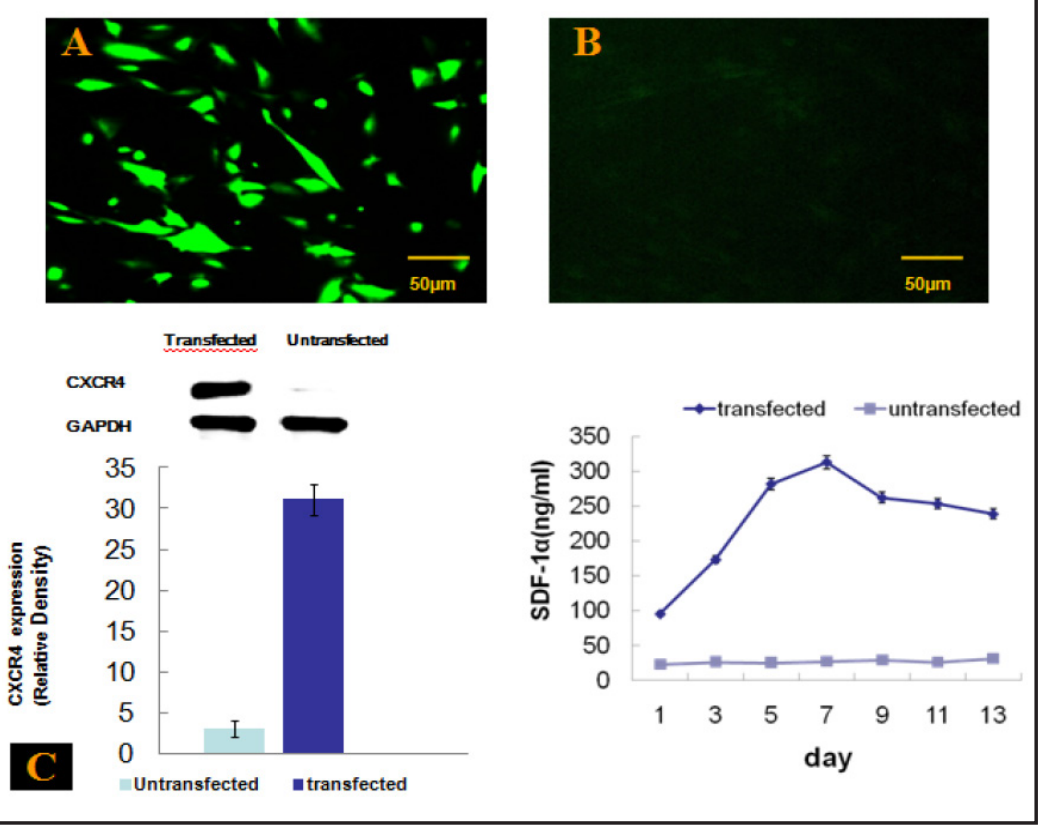

Fig. 3. Viability of the free transplanted fat tissues after 6 months. A: Surviving transplanted fat under the skin of a nude mouse. B: Excised fat tissue. Each mouse was injected subcutaneously in 4 spots using a sharp 16-gauge needle $(0.5 \mathrm{ml} /$ spot). Fat tissues were mixed with $0.1 \mathrm{ml}$ of $1 \times 107 / \mathrm{ml}$ GFP-labeled CXCR4-transfected HBASCs (group A), $0.1 \mathrm{ml}$ of $1 \times 107$ $/ \mathrm{ml}$ GFP-labeled HBASCs (group B), 0.1 $\mathrm{ml}$ of $1 \mu \mathrm{g} / \mathrm{ml} \mathrm{VEGF} \mathrm{(group} \mathrm{C),} \mathrm{or} 0.1 \mathrm{ml}$ of Dulbecco's Modified Eagle's Medium (DMEM) (group D) and then randomly injected into each spot. Each mouse could potentially receive all four fat mixtures. C: The survival ratio of transplanted fat tissues was calculated using the following formula: survival volume/previous volume $(0.5 \mathrm{ml})$. The survival ratios of group
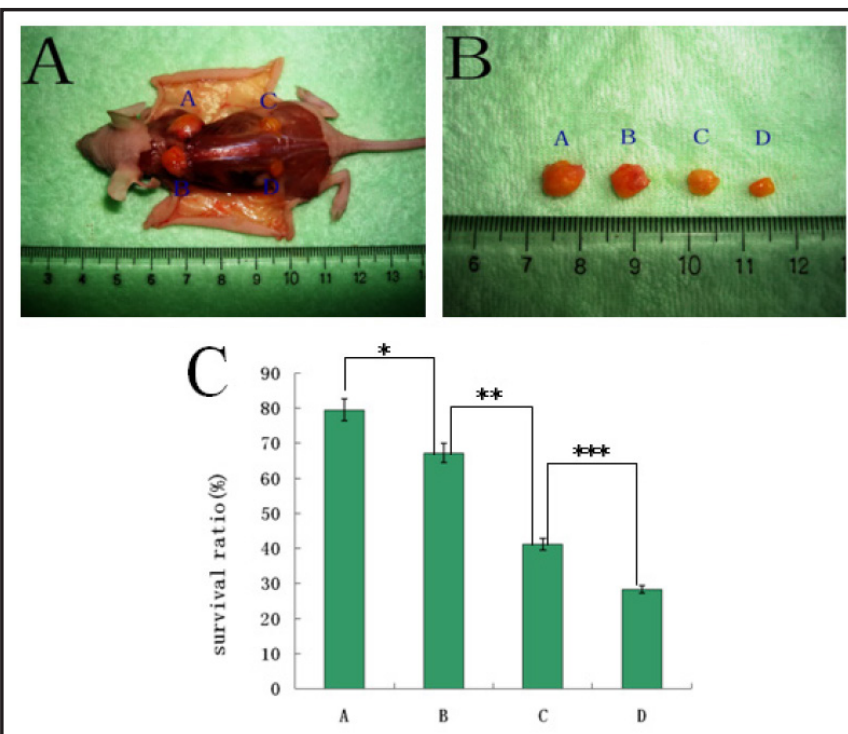

A, group B, group C and group D were $79.5 \pm 8.3 \%, 67.2 \pm 5.9 \%, 41.2 \pm 5.1 \%$, and $28.3 \pm 4.5 \%(\mathrm{n}=20)$, respectively. Significant differences between the groups (according to paired t-tests) are shown. ${ }^{*}<0.05$, ${ }^{* *} \mathrm{P}<0.05,{ }^{* * *} \mathrm{P}<0.05$.

Seventy-two hours after CXCR4 gene transfection, CXCR4 protein expression was measured in the treatment and control groups using western blot analysis. The expression of CXCR4 protein was significantly increased in the treatment group compared with the control group; specifically, the relative density of CXCR4 protein was 7.36-fold greater in the treatment groups than in the control group according to western blot analysis $(\mathrm{P}<0.001$, Fig. 2C). Moreover, the level of SDF- $1 \alpha$ in the two groups was quantified every other day after cell seeding. The human SDF- $1 \alpha$ levels in the culture medium of SDF- $1 \alpha$-transfected HBASCs at $1,3,5,7,9,11$, and 13 days after gene transfection increased significantly over time and peaked on day 7 (Fig. 2D and Table 2). In contrast, markedly low levels of SDF- $1 \alpha$ were detected in the culture medium of untransfected HBASCs $(\mathrm{P}<0.01)$. 


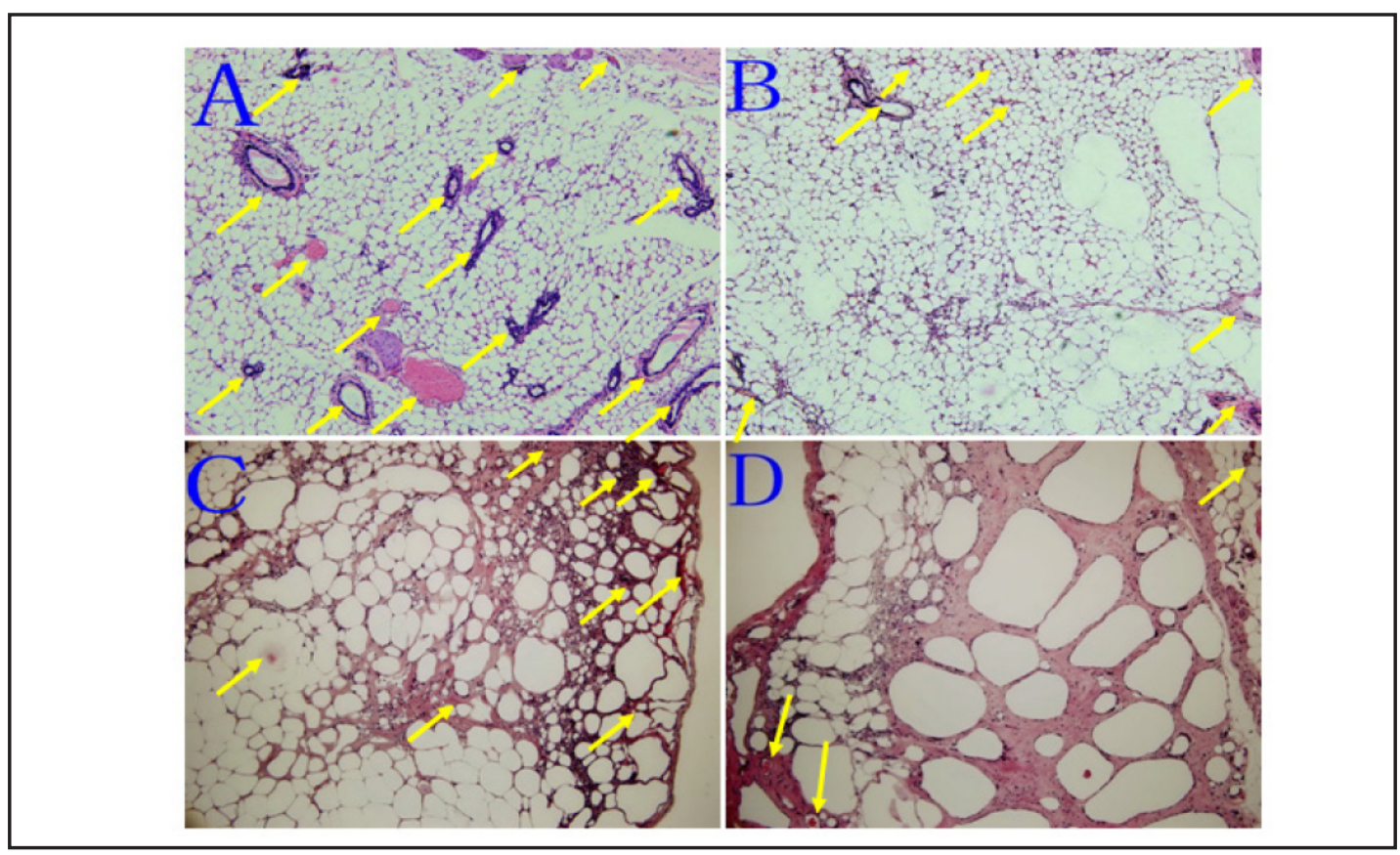

Fig. 4. Histological evaluation of free transplanted fat tissue after 6 months ( $40 \times$ magnification). A: Transplants from group A consisted predominantly of mature adipose tissue and had significantly lower levels of fat necrosis and fibrosis compared to those from groups C and D; B: Transplants from group B also consisted predominantly of mature adipose tissue and had significantly lower levels of fat necrosis and fibrosis compared to those from groups C and D; C: Transplants from group C showed obvious fibrosis, numerous mixed cell infiltrations, and fat necrosis; D: Transplants from group D showed excessive fibrosis and fat necrosis; The yellow arrows indicate neovascular capillaries.

\section{Assessment of the fat tissue survival ratio}

The fat tissues were mixed with GFP-labeled CXCR4-transfected HBASCs (group A), GFP-labeled HBASCs (group B), VEGF (group C), or DMEM (group D). Each mouse could be injected with any combination of the four fat mixtures, and one of these four fat mixtures was injected into each spot in a random fashion. None of the animals died during the first 6 months after transplantation, at which point, the transplanted fats were excised as shown in Fig. 3. The volumes of the transplants were measured using the liquid overflow method, and these volumes were used to calculate the survival ratio using the following formula: survival volume/previous volume $(0.5 \mathrm{ml})$. The survival ratios for groups A, B, C, and D were $79.5 \pm$ $8.3 \%, 67.2 \pm 5.9 \%, 41.2 \pm 5.1 \%$, and $28.3 \pm 4.5 \%(n=20)$, respectively. Differences between the groups were all significant (Fig. 3).

\section{Histological evaluation of fat transplants}

The DMEM control transplants (group D) exhibited excessive fibrosis and fat necrosis (Fig. 4D), whereas the VEGF-treated transplants (group C) showed obvious fibrosis, numerous mixed cell infiltrations, and fat necrosis (Fig. 4C). In contrast, the transplants mixed with GFPlabeled, CXCR4-transfected HBASCs (group A) and GFP-labeled HBASCs (group B) consisted predominantly of surviving mature adipose tissue and had significantly lower levels of fat necrosis and fibrosis; both transplants also exhibited the histological structure of normal fat tissue (Fig. 4A and B).

\section{Capillary density of fat transplants in each group}

Histological evaluation of 10 fields per section taken from the center of the surviving fat tissue allowed us to determine the capillary density, which is an index of neovascularization. 
Fig. 5. Capillary density in surviving transplanted fat tissue. Histological evaluation of 10 fields per section taken from the center of the surviving fat tissue revealed that the capillary density was much higher in the transplants mixed with CXCR4-transfected HBASCs (group A) than in the other three transplant groups. These differences were significant according to a paired t-test. ${ }^{*} \mathrm{P}<0.05,{ }^{* *} \mathrm{P}<0.05,{ }^{* * *} \mathrm{P}<0.05$.
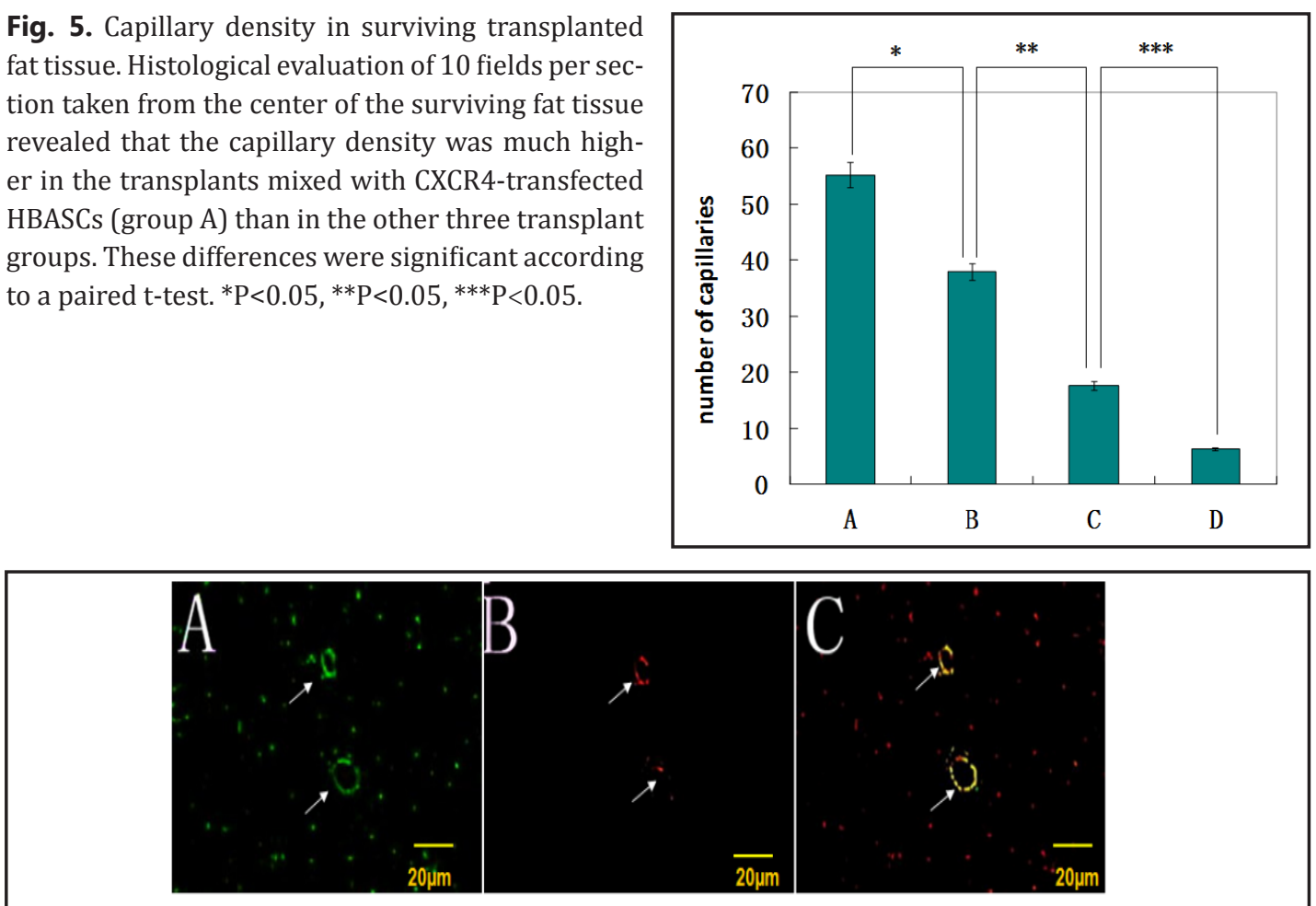

Fig. 6. Origin of the endothelial cells in neovascular capillaries $(100 \times$ magnification $)$ A: Survival of the GFP-labeled HBASCs in the transplants was demonstrated by the presence of red fluorescent cells. These green fluorescent cells could be detected not only in capillary-like structures but also around the mature adipose tissue. B: Staining of the transplant sections with a Cy3-labeled mAb targeted against the endothelial cell marker CD31 revealed the neovascular capillary endothelial cells (red fluorescence). C: Merging of the green fluorescence of GFP with the red fluorescence of CD31 revealed three yellow endothelial cells, indicating that these endothelial cells had differentiated from GFP-labeled HBASCs. Scale bars: $20 \mu \mathrm{m}$.

Capillary density was much higher in the CXCR4-transfected HBASCs transplants than in the other three transplants (Fig. 4A). The transplants mixed with untransfected HBASCs also had a reasonably good capillary density (Fig. 4B). In contrast, few capillaries could be detected in the transplants from groups $C$ and D (Fig. 4C and D). These differences were significant according to a paired t-test $(\mathrm{n}=10, P<0.05$, Fig. 5).

Origin of the endothelial cells in the neovascular capillaries

Survival of the transplanted HBASCs was confirmed by the presence of the green fluorescent GFP-labeled cells. These cells could be detected not only in the capillary-like structures but also around the mature adipose tissue (Fig. 6A). To determine whether any of the endothelial cells in the capillaries were derived from the exogenous GFP-labeled HBASCs, we stained the transplant sections with an Ig Cy3-labeled antibody against CD31, which is an endothelial cell marker (Fig. 6B). Merging the green fluorescence of GFP with the red fluorescence of CD31 revealed three yellow endothelial cells, indicating that these endothelial cells had differentiated from GFP-labeled HBASCs (Fig. 6C).

The expression of CXCR4 and SDF-1 $\alpha$ genes in fat transplants

After 6 months, the relative mRNA expression of CXCR4 and SDF- $1 \alpha$ in fat transplants in each group was detected using real-time quantitative PCR analysis. The mRNA expression of CXCR4 and SDF- $1 \alpha$ was much higher in the CXCR4-transfected HBASCs transplants than in the other three transplants, and the two genes also had reasonably higher expression levels in the transplants mixed with untransfected HBASCs. In contrast, the mRNA expression of 
Fig. 7. After 6 months in each group, the mRNA expression levels of CXCR4 and SDF- $1 \alpha$ were much higher in the CXCR4-transfected HBASCs transplants than in the other three transplants, and these two genes also exhibited reasonably higher expression in the transplants mixed with untransfected HBASCs. In contrast, minimal CXCR4 and SDF-1 $\alpha$ mRNA expression could be detected in the transplants from groups $\mathrm{C}$ and $\mathrm{D}$. These differences were significant according to a paired t-test. ${ }^{a} \mathrm{P}<0.05,{ }^{\mathrm{a}^{\prime}} \mathrm{P}<0.05,{ }^{\mathrm{b}} \mathrm{P}<0.05,{ }^{\mathrm{b}^{\prime}} \mathrm{P}<0.05$, ${ }^{\mathrm{c}} \mathrm{P}<0.05,{ }^{\prime} \mathrm{P}<0.05$.

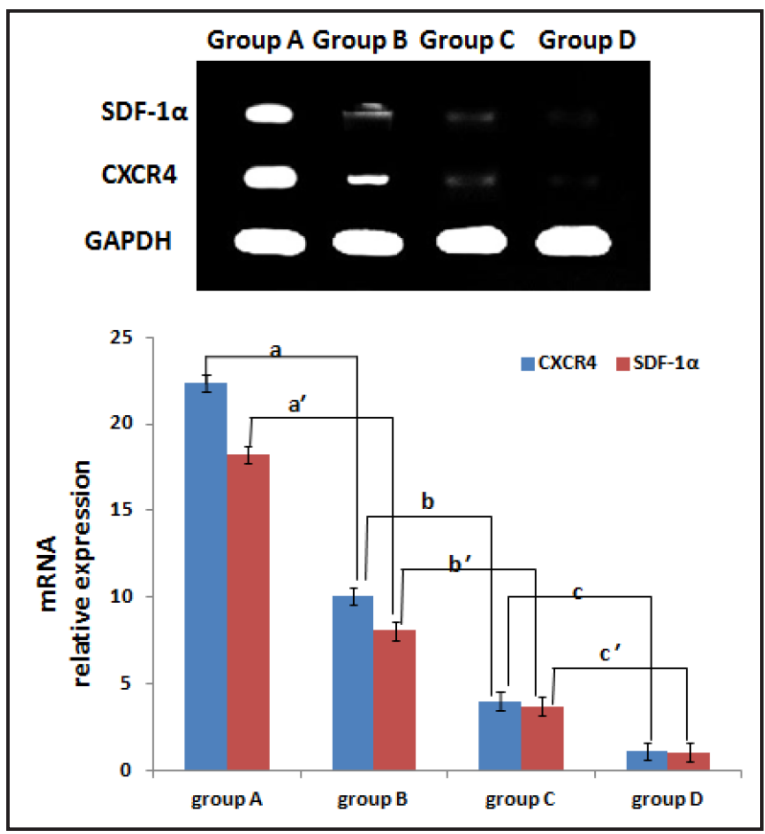

CXCR4 and SDF- $1 \alpha$ was low in the transplants from groups $C$ and D. These differences were significant according to a paired t-test ( $\mathrm{n}=20, P<0.05$, Fig. 7).

\section{Discussion}

Free fat grafts have been used for soft tissue augmentation for more than 100 years because they exhibit many qualities of an ideal filler. They are autologous and completely biocompatible. Neuber was the first author to describe the use of autologous fat as a filling material in 1893, and since the first attempts, the results of free fat autotransplantation have been disappointing [20]. Implanted fat resorbs at an unpredictable rate that ranges from $20 \%$ to $90 \%$, requiring overcorrection and additional grafting [21]. Various studies have been performed to increase the survival of free fat grafts. In 1992, Eppley et al. added basic fibroblast growth factor (bFGF) delivered by dextran beads to improve fat graft survival [22]. Studies have also found that angiogenic factors, such as VEGF and SDF-1, are important for revascularization during vascularized tissue engineering [23].

Fat tissue is a large and diffuse tissue with high metabolic activity. Histological studies have suggested that revascularization of autologous fat transplants only occurs after $48 \mathrm{~h}$ [24]. This delay appears to critically impair the survival of the fat cells,which undergo degenerative changes,including the destruction of their nucleus and cell membranes. After this cell destruction, fatty cysts develop and the fat gradually becomes absorbed [25]. Thus, early and abundant neovasculization seems to be the key to the survival of free fat transplants,which in turn leads to good transplant outcomes.

Previous studies have shown that SDF-1 exerts one of the strongest chemotactic effects on BMSCs, and combined with the SDF-1 receptor CXCR4, the SDF-1/CXCR4 biological axis plays an important role in the process of tissue/organ wound repair [26]. Organ healing, i.e., that of the heart, liver, and kidney, is related to the concentration of SDF-1 and its chemoattractant effect on ASCs. Thus, local variation in the SDF-1 concentration in wound areas can affect ASCs mobilization, homing, and aggregation [27-29]. Although primary BMSCs express high levels of CXCR4 in vitro, their surface CXCR4 expression is gradually reduced [30-31] with extended passages until it eventually becomes low or even nonexistent, which impairs the migration of BMSCs toward SDF-1 [32].

A number of adenoviral-based therapies have been tested in clinical trials. Therapeutic approaches have included the use of oncolytic viruses and gene therapy with various targets, 
including TK, p53, and IFN- $\beta$. To date, improvements in the survival and progression-free survival have not been achieved using adenoviral-based therapies; however, additional trials are forthcoming. Gene therapy applications using adenoviruses have typically used serotypes 2 and 5, which are classified under adenovirus species type C. Progress in this area has proceeded in two stages. Initially, first-generation adenoviral vectors (Ads) were produced by deletion of the E1, and sometimes E3, region of the viral genome, thereby largely eliminating the ability of the virus to express viral genes within infected cells. This step was necessary to reduce the toxicity associated with adenovirus infection. The therapeutic transgene was then inserted into the E1 region. The drawbacks of first-generation Ads included the residual expression of viral proteins, which was associated with a significant immune response, and a loss of therapeutic transgene expression [33]. Additionally, they can only accommodate therapeutic transgenes that are no larger than $8 \mathrm{~kb}$. The latest generation Ads (i.e., highcapacity helper-dependent adenoviral vectors (HC-Ads)) have been engineered to remove all endogenous viral coding regions from the genome of the vector [34]. The immune response generated by HC-Ads is not as significant as that generated by first-generation vectors, and they also allow much larger inserts (approximately $35 \mathrm{~kb}$ maximum cloning capacity) [35]. Importantly, HC-Ads are capable of eliciting long-term transgene expression, even in the presence of an anti-Ad systemic immune response, which has been shown to curtail transgene expression from first-generation Ads [36]. With established methods for modifying viral genomes and the technology to carry out cell culture-based production and amplification of the vectors, it is possible to remove nearly all native viral DNA and replace it with novel DNA sequences for therapeutic purposes. This flexibility allows for the production of non-replicating Ad viruses with completely engineered genomes that are suitable for gene therapy applications for certain diseases in human patients [37].

Cell therapy is a technology in which autologous, allogeneic or xenogeneic somatic living cells are transplanted into patients for therapeutic, diagnostic or preventive purposes. Following recent developments in the stem cell research field, cell therapy has been extended to assist the revascularization of transplanted tissue or promote wound healing [38]. It has been shown that BMSCs [39], ASCs [40] and endothelial progenitor cells [41] are all capable of promoting the revascularization of ischemic tissue. However, among these sources, ASCs are ideal in many respects: they are easily harvested and handled, and they multiply readily, non-invasively, and effectively [42-43]. Furthermore, ASCs have been shown to exhibit angiogenic characteristics and to differentiate into vascular endothelial cells under experimental conditions [44]. Cell and gene therapies have been proven effective as a means of promoting neovascularization in various animal models. These two types of therapies may also be useful when employed together. Although advances have been made in gene therapy for the immunological reconstitution of patients with severe combined immune deficiency using hematopoietic stem/progenitor cells (HSPCs) transduced with viral vectors, in a clinical setting, a subset of patients subsequently develop leukemia, most likely due to the unwanted activation of an oncogene. Therefore, Hilal Gul-Uludag et al. indicated that cationic liposome-mediated delivery technology would overcome these viral vector-related drawbacks under certain conditions, despite its low and transient transfection efficiency. Cationic liposome-mediated delivery technology could also be used to express therapeutic genes safely for a short period or to enhance HSPCs expansion, differentiation, and survival via the overexpression or silencing of specific genes. It was suggested that IBAfect-mediated in vitro gene delivery to overexpress CXCR4 on HSPCs is a safe and efficient technique that offers great potential to improve the efficacy of HSPCs transplantation and gene therapy protocols [45].

Taken together, these observations led us to examine whether mixing fat transplants with HBASCs would improve transplant survival. We found that mixing the fat tissues with autologous HBASCs before free fat transplantation significantly increased capillary density and viability. Although it remains unclear how HBASCs enhance the survival of fat transplants, our data support a few possibilities. First, we found that some of the CD31-positive endothelial cells in the fat tissues were GFP-positive, indicating that these cells had differentiated from the 
HBASCs. Differentiation of ASCs into vascular endothelial cells may promote vasculogenesis, thereby enhancing transplant survival. Second, we observed adipogenic differentiation of the GFP-labeled HBASCs in the surviving fat tissue, indicating that some of the adipocytes in the tissue were derived from the exogenous HBASCs. Thus, the differentiation of some HBASCs into mature adipocytes that partially form the fat transplant may compensate for any early loss of transplanted adipocytes. Third, because the SDF- $1 \alpha$-secreting HBASCs enhanced fat transplant survival to an even greater extent compared with that of the untransfected HBASCs, it is possible that the hypoxic conditions to which the untransfected HBASCs were exposed early after transplantation caused them to release soluble angiogenic factors, such as VEGF and SDF- $1 \alpha$, that then promoted early transplant neovascularization and enhanced adipocyte survival. In this study, our data revealed that control transplant survival was $28.3 \pm 4.5 \%$. Mixing CXCR4-transfected and untransfected HBASCs significantly increased transplant survival $(79.5 \pm 8.3 \%$ and $67.2 \pm 5.9 \%$, respectively), whereas VEGF-transfected HBASCs were less effective in this regard (41.2 $\pm 5.1 \%)$. Histological analysis revealed that both types of HBASCs-treated transplants consisted primarily of adipose tissue, unlike the control transplants, and also exhibited significantly less fat necrosis and fibrosis. The CXCR4transfected HBASCs-treated transplants had a significantly higher capillary density than did the other transplants and contained GFP and CD31 double-positive cells (i.e., ASCs-derived endothelial cells). However, further study of graft complexes comprising HBASCs and free fat tissue for in vitro delivery is needed.

\section{Conclusions}

This study demonstrated that HBASCs can enhance the survival and quality of transplanted free fat tissues and that CXCR4 transfection of the HBASCs augments this effect. Stimulation of angiogenesis and decreased fat cell apoptosis through the recruitment of endothelial progenitor cells (EPCs) and increased graft revascularization represent potential mechanisms underlying the improved long-term survival of free fat transplants following CXCR4-transfected HBASCs treatment. We also showed that combining HBASCs cell therapy with CXCR4 gene therapy achieved a better effect than HBASCs therapy alone. We conclude that HBASCs cell therapy combined with CXCR4 gene therapy is highly effective in improving the survival of transplanted free fat tissues.

\section{Acknowledgments}

This work was financially supported by the China Postdoctoral Science Foundation (No. 20090450910) and the Medical Scientific Research Foundation of Guangdong Province, China (No. A2011739 and A2012814). The authors thank the Research Center of Tissue Engineering, Southern Medical University for their support. Special thanks are due to Professor Shan Jiang.

\section{Disclosure Statement}

None of the authors have any financial relationships to disclose.

\section{References}

1 Condé-Green A, Baptista LS, de Amorin NF, de Oliveira ED, da Silva KR, Pedrosa Cda S, Borojevic R, Pitanguy I: Effects of centrifugation on cell composition and viability of aspirated adipose tissue processed for transplantation. Aesthet Surg J 2010;30:249-255.

-2 Boschert MT, Beckert BW, Puckett CL, Concannon MJ: Analysis of lipocyte viability after liposuction. Plast Reconstr Surg 2002;109:761-765; discussion 766-767. 


\section{Cellular Physiology Cell Physiol Biochem 2014;34:2091-2104 and Biochemistry \\ Xu et al.: ASCs Transfected with CXCR4 Enhance Viability in Fat Graft}

- 3 Galiè M, Pignatti M, Scambi I, Sbarbati A, Rigotti G: Comparison of different centrifugation protocols for the best yield of adipose-derived stromal cells from lipoaspirates. Plast Reconstr Surg 2008;122:233e-234e.

-4 Suga H, Matsumoto D, Inoue K, Shigeura T, Eto H, Aoi N, Kato H, Abe H, Yoshimura K: Numerical measurement of viable and nonviable adipocytes and other cellular components in aspirated fat tissue. Plast Reconstr Surg 2008;122:103-114.

-5 Phull MK, Eydmann T, Roxburgh J, Sharpe JR, Lawrence-Watt DJ, Phillips G, Martin Y: Novel macromicroporous gelatin scaffold fabricated by particulate leaching for soft tissue reconstruction with adiposederived stem cells. J Mater Sci Mater Med 2013;24:461-467.

6 Yoshimura K, Sato K, Aoi N, Kurita M, Hirohi T, Harii K: Cell-assisted lipotransfer for cosmetic breast augmentation: supportive use of adipose-derived stem/stromal cells. Aesthetic Plast Surg 2008;32:48-55; discussion 56-57.

7 Yoshimura K, Sato K, Aoi N, Kurita M, Inoue K, Suga H, Eto H, Kato H, Hirohi T, Harii K: Cell-assisted lipotransfer for facial lipoatrophy: efficacy of clinical use of adipose-derived stem cells. Dermatol Surg 2008;34:1178-1185.

8 Schafer ME, Hicok KC, Mills DC, Cohen SR, Chao JJ: Acute adipocyte viability after third-generation ultrasound-assisted liposuction. Aesthet Surg J 2013;33:698-704.

-9 Minn KW, Min KH, Chang H, Kim S, Heo EJ: Effects of fat preparation methods on the viabilities of autologous fat grafts. Aesthetic Plast Surg 2010;34:626-631.

-10 Suszynski TM, Sieber DA, Cunningham BL, Van Beek AL: Implications of oxygenation in fat grafting. Plast Reconstr Surg 2014;133:731e-733e.

11 Luo S, Hao L, Li X, Yu D, Diao Z, Ren L, Xu H: Adipose tissue-derived stem cells treated with estradiol enhance survival of autologous fat transplants. Tohoku J Exp Med 2013;231:101-110.

-12 Tepper OM, Galiano RD, Kalka C, Gurtner GC: Endothelial progenitor cells: the promise of vascular stem cells for plastic surgery. Plast Reconstr Surg 2003;111:846-854.

13 Lee DW, Jeon YR, Cho EJ, Kang JH, Lew DH: Optimal administration routes for adipose-derived stem cells therapy in ischaemic flaps. J Tissue Eng Regen Med 2014;8:596-603.

14 Gao W, Qiao X, Ma S, Cui L: Adipose-derived stem cells accelerate neovascularization in ischaemic diabetic skin flap via expression of hypoxia-inducible factor-1 $\alpha$. J Cell Mol Med 2011;15:2575-2585.

-15 Zamora DO, Natesan S, Becerra S, Wrice N, Chung E, Suggs LJ, Christy RJ: Enhanced wound vascularization using a dsASCs seeded FPEG scaffold. Angiogenesis 2013;16:745-757.

16 Horuk R: Chemokine receptors. Cytokine Growth Factor Rev 2001;12:313-335.

17 Döring Y, Pawig L, Weber C, Noels H: The CXCL12/CXCR4 chemokine ligand/receptor axis in cardiovascular disease. Front Physiol 2014;5:212.

18 Balabanian K, Lagane B, Infantino S, Chow KY, Harriague J, Moepps B, Arenzana-Seisdedos F, Thelen M, Bachelerie F: The chemokine SDF-1/CXCL12 binds to and signals through the orphan receptor RDC1 in T lymphocytes. J Biol Chem 2005;280:35760-35766.

19 Janowski M: Functional diversity of SDF-1 splicing variants. Cell Adh Migr 2009;3:243-249.

20 Billings E Jr1, May JW Jr: Historical review and present status of free fat graft autotransplantation in plastic and reconstructive surgery. Plast Reconstr Surg 1989;83:368-381.

21 Mineda K, Kuno S, Kato H, Kinoshita K, Doi K, Hashimoto I, Nakanishi H, Yoshimura K: Chronic inflammation and progressive calcification as a result of fat necrosis: the worst outcome in fat grafting. Plast Reconstr Surg 2014;133:1064-1072.

22 Eppley BL, Sidner RA, Platis JM, Sadove AM: Bioactivation of free-fat transfers: a potential new approach to improving graft survival. Plast Reconstr Surg 1992;90:1022-1030.

-23 Simcock JW, Penington AJ, Morrison WA, Thompson EW, Mitchell GM: Endothelial precursor cells home to a vascularized tissue engineering chamber by application of the angiogenic chemokine CXCL12. Tissue Eng Part A 2009;5:655-664.

24 FAWCETT DW: Histological observations on the relation of insulin to the deposition of glycogen in adipose tissue. Endocrinology 1948;42:454-467.

-25 Kato H, Mineda K, Eto H, Doi K, Kuno S, Kinoshita K, Kanayama K, Yoshimura K: Degeneration, regeneration, and cicatrization after fat grafting: dynamic total tissue remodeling during the first 3 months. Plast Reconstr Surg 2014;133:303e-313e.

26 Seeger FH, Rasper T, Fischer A, Muhly-Reinholz M, Hergenreider E, Leistner DM, Sommer K, Manavski Y, Henschler R, Chavakis E, Assmus B, Zeiher AM, Dimmeler S: Heparin disrupts the CXCR4/SDF-1 axis and 
impairs the functional capacity of bone marrow-derived mononuclear cells used for cardiovascular repair. Circ Res 2012;111:854-862.

27 Jin Q, Giannobile WV: SDF-1 enhances wound healing of critical-sized calvarial defects beyond self-repair capacity. PLoS One 2014;9:e97035.

28 Wang Z, Moran E, Ding L, Cheng R, Xu X, Ma JX: PPAR $\alpha$ regulates mobilization and homing of endothelial progenitor cells through the HIF-1 $\alpha /$ SDF-1 pathway. Invest Ophthalmol Vis Sci 2014;55:3820-3832.

29 Togel FE, Westenfelder C: Role of SDF-1 as a regulatory chemokine in renal regeneration after acute kidney injury. Kidney Int 2011;1:S87-89.

- 30 Brenner S, Whiting-Theobald N, Kawai T, Linton GF, Rudikoff AG, Choi U, Ryser MF, Murphy PM, Sechler JM, Malech HL: CXCR4-transgene expression significantly improves marrow engraftment of cultured hematopoietic stem cells. Stem Cells 2004;22:1128-1133.

-31 Wynn RF, Hart CA, Corradi-Perini C, O'Neill L, Evans CA, Wraith JE, Fairbairn LJ, Bellantuono I: A small proportion of mesenchymal stem cells strongly expresses functionally active CXCR4 receptor capable of promoting migration to bone marrow. Blood 2004;104:2643-2645.

32 Honczarenko M, Le Y, Swierkowski M, Ghiran I, Glodek AM, Silberstein LE: Human bone marrow stromal cells express a distinct set of biologically functional chemokine receptors. Stem Cells 2006;24:1030-1041. Volpers C, Kochanek S: Adenoviral vectors for gene transfer and therapy. J Gene Med 2004;6:S164-171. Kochanek S: High-capacity adenoviral vectors for gene transfer and somatic gene therapy. Hum Gene Ther 1999;10:2451-2459.

-35 Lowenstein PR, Castro MG: Genetic engineering within the adult brain: implications for molecular approaches to behavioral neuroscience. Physiol Behav 2001;73:833-839.

-36 Xiong W, Goverdhana S, Sciascia SA, Candolfi M, Zirger JM, Barcia C, Curtin JF, King GD, Jaita G, Liu C, Kroeger K, Agadjanian H, Medina-Kauwe L, Palmer D, Ng P, Lowenstein PR, Castro MG: Regulatable gutless adenovirus vectors sustain inducible transgene expression in the brain in the presence of an immune response against adenoviruses. J Virol 2006;80:27-37.

- 37 Puntel M, A K M GM, Farrokhi C, Vanderveen N, Paran C, Appelhans A, Kroeger KM, Salem A, Lacayo L, Pechnick RN, Kelson KR, Kaur S, Kennedy S, Palmer D, Ng P, Liu C, Krasinkiewicz J, Lowenstein PR, Castro MG: Safety profile, efficacy, and biodistribution of a bicistronic high-capacity adenovirus vector encoding a combined immunostimulation and cytotoxic gene therapy as a prelude to a phase I clinical trial for glioblastoma. Toxicol Appl Pharmacol 2013;268:318-330.

-38 Uysal CA, Tobita M, Hyakusoku H, Mizuno H: The Effect of Bone-Marrow-Derived Stem Cells and Adipose-Derived Stem Cells on Wound Contraction and Epithelization. Adv Wound Care (New Rochelle) 2014;3:405-413.

-39 Karatasakis G, Leontiadis E, Peristeri I, Manginas A, Goussetis E, Graphakos S, Papadakis E, Cokkinos DV: Intracoronary infusion of selected autologous bone marrow stem cells improves longitudinal myocardial strain and strain rate in patients with old anterior myocardial infarction without recent revascularization. Eur J Echocardiogr 2010;11:440-445.

40 Shevchenko EK, Makarevich PI, Tsokolaeva ZI, Boldyreva MA, Sysoeva VY, Tkachuk VA, Parfyonova YV: Transplantation of modified human adipose derived stromal cells expressing VEGF165 results in more efficient angiogenic response in ischemic skeletal muscle. J Transl Med 2013;11:138.

41 Sheu JJ, Lin PY, Sung PH, Chen YC, Leu S, Chen YL, Tsai TH, Chai HT, Chua S, Chang HW, Chung SY, Chen CH, Ko SF, Yip HK: Levels and values of lipoprotein-associated phospholipase A2, galectin-3, RhoA/ROCK, and endothelial progenitor cells in critical limb ischemia: pharmaco-therapeutic role of cilostazol and clopidogrel combination therapy. J Transl Med 2014;12:101.

-42 Dhanasekaran M, Indumathi S, Poojitha R, Kanmani A, Rajkumar JS, Sudarsanam D: Plasticity and banking potential of cultured adipose tissue derived mesenchymal stem cells. Cell Tissue Bank 2013;14:303-315.

43 Cui SE, Li HM, Liu DL, Nan H, Xu KM, Zhao PR, Liang SW: Human breast adipose derived stem cells: characterization and differentiation into mammary gland like epithelial cells promoted by autologous activated platelet rich plasma. Mol Med Rep 2014;10:605-614.

-44 Colazzo F, Alrashed F, Saratchandra P, Carubelli I, Chester AH, Yacoub MH, Taylor PM, Somers P: Shear stress and VEGF enhance endothelial differentiation of human adipose-derived stem cells. Growth Factors 2014;32:139-149.

-45 Gul-Uludag H, Xu P, Marquez-Curtis LA, Xing J, Janowska-Wieczorek A, Chen J: Cationic liposome-mediated CXCR4 gene delivery into hematopoietic stem/progenitor cells: implications for clinical transplantation and gene therapy. Stem Cells Dev 2012;21:1587-1596. 